\title{
THE METABOLIC CLEARANCE RATE OF ALDOSTERONE IN PREGNANT AND NONPREGNANT SUBJECTS ESTIMATED BY BOTH SINGLE- INJECTION AND CONSTANT-INFUSION METHODS *
}

\author{
By J. F. TAIT, B. LITTLE, S. A. S. TAIT, AND C. FLOOD
}

(From the Worcester Foundation for Experimental Biology, Shrewsbury, and the Department of Obstetrics and Gynecology, Harvard Medical School, Boston City Hospital, Boston, Mass.)

(Submitted for publication March 13, 1962 ; accepted August 1, 1962).

Jones and colleagues (1) found that the pattern of urinary metabolites of aldosterone was changed in pregnant compared with nonpregnant subjects. The ratio, however, of the secretion rate to the urinary free aldosterone, which was taken to indicate the over-all metabolic rate, was not appreciably altered.

Daughaday (2) and Meyer (3) and their associates found that the binding of aldosterone to plasma proteins other than albumin was the same for nonpregnant and pregnant subjects and for subjects treated with small amounts of estrogens. The unaltered binding, unlike that of cortisol, might suggest that the over-all metabolism of aldosterone is unchanged in pregnancy.

Tait and co-workers (4) described methods for the calculation of volumes of distribution and rate constants by measurement of the plasma radioactivity, as aldosterone, as a function of time after a single injection of the tritiated hormone. In addition, the ratio of the secretion rate to the plasma steroid concentration, which is a measure of the over-all metabolic process, could be calculated both after a single injection and after constant infusion of radioactive steroid. This ratio was previously termed a "turnover rate" (4), but as it has the dimensions of volume divided by time, it will henceforward be referred to as the "metabolic clearance rate" (MCR) of the steroid. In the present paper, the singleinjection and constant-infusion methods for estimating MCR are compared for both pregnant and nonpregnant subjects. The MCR

* Work supported by U. S. Public Health Grants A-3197, A-3598, and A-3490, U. S. Atomic Energy Grant AT (30-1)918, American Cancer Society (Massachusetts Division) Institutional Grant 1, and Josiah Macy Jr. Foundation Grant. Some of these results have been reported in preliminary form (Program of the 43rd Meeting, Endocr. Soc., 1961, pp. 16-17 [abstract]). values for whole blood after constant infusion have also been estimated.

\section{MATERIALS AND METHODS}

The methods described by Tait and associates (4) were employed without significant modification. In the later experiments, the liquid scintillation counting was carried out by a Tracerlab model LSC- 20 with two separate amplifiers so that tritium and $\mathrm{C}^{14}$ could be assayed simultaneously at their respective balance points. Every sample from plasma was counted simultaneously for $\mathrm{H}^{3}$ and $\mathrm{C}^{14}$ and for at least 300 minutes. The usual counting error for the $\mathrm{C}^{14} / \mathrm{H}^{3}$ ratio was 5 per cent.

In the single-injection method, $2 \mu \mathrm{c}(0.1 \mu \mathrm{g})$ of $7-\mathrm{H}^{3}-d$ aldosterone was administered intravenously, and plasma was collected $7.5,15,22.5,30,50$, and 70 minutes later. The results could then be expressed by the equation $x^{1}$ (the concentration of radioactivity as aldosterone in plasma $)=A^{1} e^{-\alpha \mathrm{t}}+B^{1} e^{-\beta \mathrm{t}} . \quad A^{1}, B^{1}, \alpha$, and $\beta$ were estimated by the method of least squares. The initial volume of distribution, $V_{1}=1 /\left(A^{1}+B^{1}\right)$, and metabolic clearance rate, $M C R=\alpha \beta /\left(A^{1}{ }_{\beta}+B^{1}{ }_{\alpha}\right)$, were then calculated (4).

In the constant-infusion method, $1 \mu \mathrm{c}$ of $7-\mathrm{H}^{3}$ - $d$-aldosterone dissolved in $10 \mathrm{ml}$ of normal saline was first injected intravenously. Thirty minutes later an intravenous infusion was started, and continued for 105 minutes. A total of $1 \mu \mathrm{c}$ dissolved in $20 \mathrm{ml}$ of normal saline was infused. The total amount of radioactivity infused was not critical, but was chosen to maintain the plasma radioactive concentration likely to be found 30 minutes after a single injection of $1 \mu \mathrm{c}$ for a typical normal subject. Blood was withdrawn $7.5,15,30,105,120$, and 135 minutes after the initial injection. The plasma was separated, added to tubes containing 4- ${ }^{14}$-aldosterone, and processed as previously described (4). In six experiments, additional blood was withdrawn at 105,120 , and 135 minutes after the single injection. Before centrifugation, a $10-\mathrm{ml}$ sample of whole blood was added to tubes containing 4-C ${ }^{14}$-aldosterone. The $4-\mathrm{C}^{14}$-aldosterone was thoroughly mixed with the tritiated hormone by freezing and thawing the whole blood several times both before and after the addition of equal volumes of water. The diluted hemolyzed blood was then extracted with $3 \times 1.2$ vol methylene dichloride and the dried extract was chromatographed on a silica gel column (5). It was then treated as previously described for plasma. The over-all recoveries were similar 
for plasma and whole blood. As will be described in the Results section, the estimates of radioactive concentrations as aldosterone in plasma or whole blood at 105, 120, and 135 minutes after continuous infusion showed no consistent trend with time away from a constant value for the same subject. The mean of these three estimates was therefore taken to calculate the MCR, which equals the rate of radioactive infusion divided by the plasma or whole blood concentration of radioactivity measured as aldosterone, or, $M C R(\mathrm{~L}$ per day $)=r(\mu \mathrm{c}$ per day $) / x^{1}{ }_{c}(\mu \mathrm{c}$ per $\mathrm{L})$.

The nonpregnant subjects were all female patients, in their reproductive years and at no consistent stage of their menstrual cycle. The pregnant subjects were at least at 36 weeks of gestation. All subjects had been hospitalized for minor disorders not relevant to this study and were receiving no medication during this test. They were all recumbent during the experiments. No subject was used more than once, to reduce the total amount of radioactivity given.

\section{THEORY}

In a previous treatment of similar data for nonpregnant subjects (4), the initial volume of distribution, MCR (then termed "turnover rate"), final volume of distribution, and various rate constants were calculated on the assumption that no extrahepatic metabolism of aldosterone occurred and that the liver could be considered as part of the inner pool in a two-compartment model. While there still seems to be no reason to doubt that these assumptions are valid for nonpregnant subjects, they cannot be applied, at present, to the pregnant state. In the general case, it is necessary to assume that a steroid hormore is metabolized in both compartments. As is shown in the Appendix, the MCR will be $\alpha \beta /\left(A^{1}{ }_{\beta}+B^{1}{ }_{\alpha}\right)$ for the single-injection and $r / x^{1}{ }_{c}$ for the continuous-infusion method, and the validity of these estimates will be independent of whether metabolism occurs in either or both compartments, provided that the hormone is secreted and the radioactive steroid is introduced into the same compartment. Whereas this is likely to be so in general, since they will both be introduced into the same circulating plasma, in pregnant subjects it is possible that the fetus must be considered as part of the outer pool and that it may both metabolize and secrete a particular steroid hormone. In view, however, of the demonstration of negligible excretion of aldosterone by adrenalectomized pregnant women maintained on small amounts of adrenal hormone (6-8) indicating the absence of significant fetal or placental secretion, the methods of calculating

TABLE I

Results of the constant infusion experiments for nonpregnant and pregnant women*

\begin{tabular}{|c|c|c|c|c|c|c|c|c|c|}
\hline \multirow[b]{3}{*}{ Subjects } & \multirow{3}{*}{$\begin{array}{c}\text { Before } \\
\text { infusioñ } \\
\text { at } \\
30 \mathrm{~min}\end{array}$} & \multicolumn{4}{|c|}{ Plasma concentration $\mathrm{H}^{3}$} & \multirow{3}{*}{$\begin{array}{c}\text { Coefficient } \\
\text { of varia- } \\
\text { tion for } \\
105,120, \\
\text { and } 135 \mathrm{~min}\end{array}$} & \multirow{3}{*}{$\begin{array}{l}\text { Rate of } \\
\text { infusion } \\
\text { lasting } \\
105 \mathrm{~min}\end{array}$} & \multirow{3}{*}{$\begin{array}{l}\text { Metabolic } \\
\text { clearance } \\
\text { rate }\end{array}$} & \multirow{3}{*}{$\begin{array}{l}\text { Error of } \\
\text { estimate } \\
\text { for } 105 \text {, } \\
120 \text {, and } \\
135 \text { min }\end{array}$} \\
\hline & & \multicolumn{4}{|c|}{ During infusion at } & & & & \\
\hline & & $105 \mathrm{~min}$ & $120 \mathrm{~min}$ & $135 \mathrm{~min}$ & $135 \mathrm{~min}$ & & & & \\
\hline & $m \mu c / L$ & $m \mu c / L$ & $m \mu c / L$ & $m \mu c / L$ & $m \mu c / L$ & $\begin{array}{l}S D / \text { Mean } \\
\times 100 \%\end{array}$ & $\mu c / d a y$ & $\underset{\text { day }}{L \text { plasma }}$ & $\begin{array}{c}S E / M e a n \\
\times 100 \%\end{array}$ \\
\hline \multicolumn{10}{|c|}{ Nonpregnant } \\
\hline Y.A. & 9.9 & 9.5 & 8.8 & 6.4 & 8.2 & 16 & 13.3 & 1620 & 11 \\
\hline K.L. & 4.7 & 6.5 & 6.0 & 4.7 & 5.7 & 13 & 12.2 & 2125 & 9 \\
\hline G.R. & 7.0 & 6.1 & 9.2 & 9.1 & 8.1 & 18 & 13.7 & 1685 & 13 \\
\hline R.B. & 8.1 & 9.3 & 9.2 & 10.3 & 9.6 & 5.5 & 14.7 & 1530 & 4 \\
\hline M.C. & 6.9 & 8.2 & 10.6 & 9.1 & 9.1 & 11 & 15.8 & 1740 & 8 \\
\hline L.B. & 14.2 & 13.3 & 14.0 & 14.6 & 14.0 & 4 & 13.7 & 1022 & 3 \\
\hline F.C. & 16.2 & 16.8 & 16.5 & 11.5 & 14.9 & 16 & 15.2 & 1020 & 11 \\
\hline \multicolumn{2}{|c|}{ Mean } & 10.0 & 10.6 & 9.4 & & & & & \\
\hline \multicolumn{10}{|l|}{ Pregnant } \\
\hline M.M. & 6.2 & 6.5 & 7.1 & 7.9 & 7.1 & 8 & 12.4 & 1704 & 6 \\
\hline E.D. & 5.4 & 8.0 & 7.7 & 6.0 & 7.2 & 12 & 12.8 & 1770 & 8.5 \\
\hline J.C. & 8.2 & 9.7 & 10.5 & 9.9 & 10.0 & 3 & 14.5 & 1450 & 2 \\
\hline J.S. & 9.6 & 11.1 & 10.1 & 10.9 & 10.7 & 2.5 & 14.7 & 1375 & 2 \\
\hline R.M. & 6.5 & 11.7 & 11.1 & 11.2 & 11.3 & 2.5 & 15.2 & 1345 & 2 \\
\hline B.O. & & 12.1 & 9.9 & 11.3 & 11.1 & 8 & 14.5 & 1306 & 6 \\
\hline R.S. & 8.7 & 8.5 & 9.2 & 7.7 & 8.5 & 7 & 14.4 & 1702 & 5 \\
\hline J.Sa & 11.7 & 11.1 & 9.9 & 10.5 & 10.5 & 5 & 14.8 & 1410 & 3.5 \\
\hline A.H. & 10.9 & 11.1 & 9.6 & 11.2 & 10.6 & 7 & 14.8 & 1396 & 5 \\
\hline \multicolumn{2}{|c|}{ Mean } & 10.0 & 9.5 & 9.6 & & & & & \\
\hline
\end{tabular}

* The concentrations of tritiated aldosterone in plasma are corrected for recovery. The actual concentrations measured were about 40 per cent of these values. 
MCR are still likely to be valid for this hormone in pregnancy. The estimate of the initial volume of distribution, $V_{1}=1\left(A^{1}+B^{1}\right)$, is also independent of the relative metabolism in the inner and outer pool. But, unless it is assumed that metabolism is zero in either the inner or outer pool $(4,9)$, the final volume of distribution and the fractional metabolic and transport-rate constants cannot be estimated. Since this assumption cannot be made for pregnant subjects, only the initial volume of distribution and MCR have been estimated.

\section{RESULTS}

The data for the constant-infusion experiments are given in Table I. No individual experiment showed a trend of values for the 30-, $105-, 120-$, and 135-minute samples that would indicate lack of equilibrium. Y.A. showed a downward trend of values, but in this case the variation of the 30-, 105-, and 120-minute concentrations was not outside the limits of expected

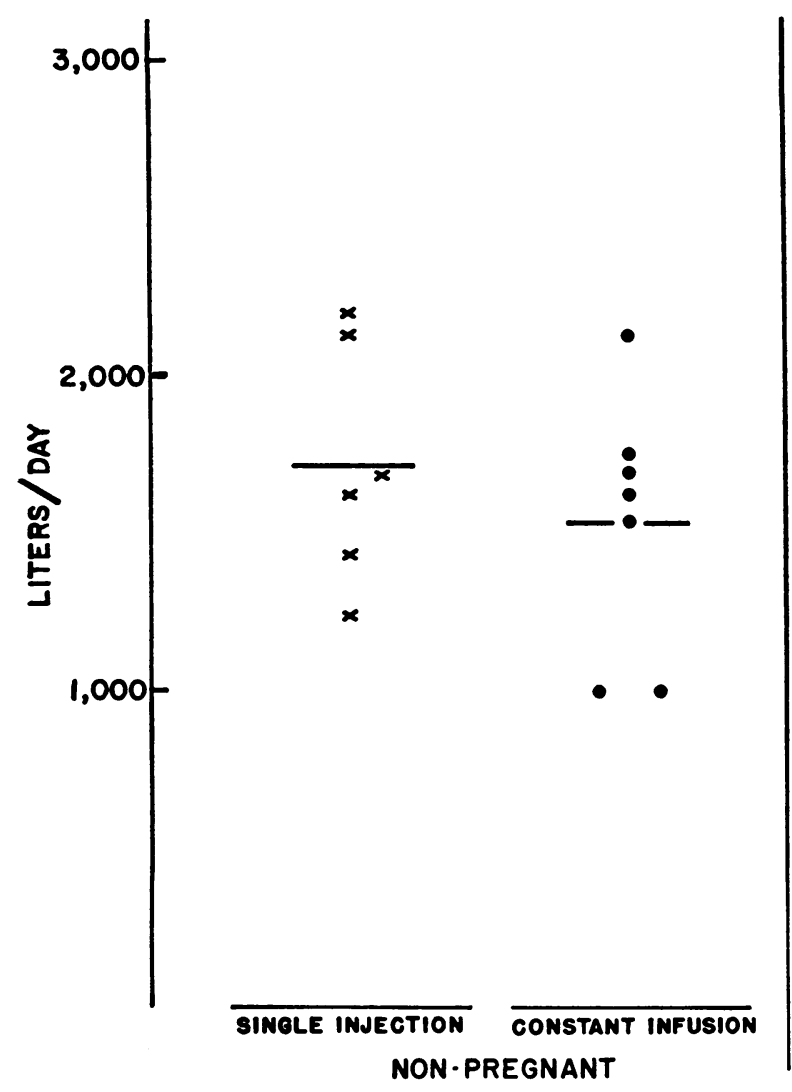

experimental error (5 per cent for statistical counting accuracy). The mean values for all 16 experiments for the radioactive concentrations at 105,120 , and 135 minute were 10.0,10.0, and $9.5 \mathrm{~m} \mu \mathrm{c}$ per liter. The variation between 105-, $120-$, and 135-minute samples for every individual experiment is shown in Table I expressed as the coefficient of variation, $\mathrm{SD} /$ mean $\times 100$ per cent. The mean coefficient for all 16 experiments was 9 per cent. Since the MCR is calculated from the mean of three such estimations, its error will be a combination of this variation $(\mathrm{SE} /$ mean $\times 100$ per cent $)$, which is 6 per cent (Table I), and the errors from pipetting and counting of standard solutions, about 2 per cent. The over-all error of a MCR estimate by constant infusion is therefore about 7 per cent. The data for the single-injection experiments and the calculated values for $\mathrm{A}^{1}, \mathrm{~B}^{1}, \alpha$, and $\beta$ were similar to those previously reported (4).

The estimates of MCR for both single-injec-

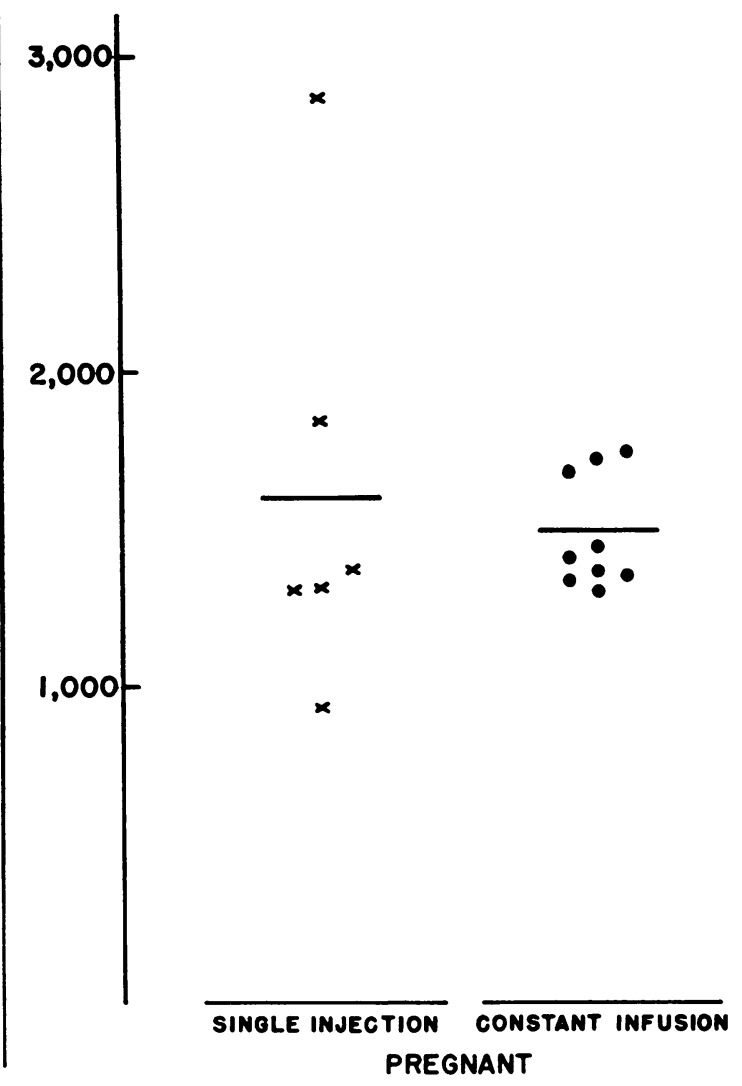

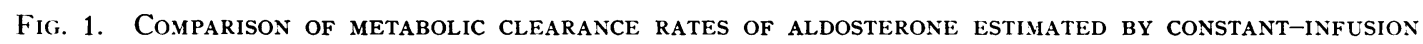

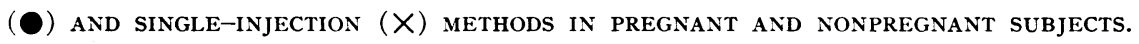


tion and constant-infusion methods and for pregnant and nonpregnant subjects are shown in Figure 1. There is no significant difference between the estimates by the two methods for normal women; the rate by single injection is $1,743 \pm 148$ (SE) L of plasma per day (6 subjects) and by constant infusion, 1,535 \pm 150 (SE) L of plasma per day (7 subjects). In normal pregnancy, the rate by single injection is $1,609 \pm 283$ (SE) L of plasma per day (6 subjects) and by constant infusion, 1,499 \pm 61 (SE) $\mathrm{L}$ of plasma per day ( 9 subjects). When the estimates made by both methods are combined, there is no significant difference between the MCR of aldosterone in nonpregnant women$1,631 \pm 106$ (SE) L of plasma per day (13 subjects) - and pregnant women near term-1,543 \pm 113 (SE) L of plasma per day (15 subjects).

Since there is no difference between the two groups, the pregnant and nonpregnant results can be combined to give the most critical comparison of the methods. The single-injection method then gives $1,676 \pm 154(\mathrm{SE})$ (12 subjects) and the constant infusion 1,515 $\pm 70(\mathrm{SE})$ $\mathrm{L}$ of plasma per day (16 subjects). The 10 per cent difference, expressed in terms of their mean value, in the estimates by the two methods is not significant $(\mathrm{p}>0.1) ; \mathrm{a} 20$ per cent difference would have been significant $(p=0.05)$.

There was also no significant difference between the initial volumes of distribution, $V_{1}$ $=1 /\left(A^{1}+B^{1}\right)$, in the nonpregnant and pregnant subjects; values were $28 \pm 2.5$ and $23 \pm$ 2.5 (SE) L, respectively (6 nonpregnant and 6 pregnant subjects).

For three nonpregnant subjects, the MCR was determined concomitantly for plasma and whole blood. The ratio in the estimates was found to be $1.51,1.37$, and 1.61 , with a mean ratio of 1.50 , which, together with the estimates of the plasma clearance rates of thirteen nonpregnant subjects, gives $2,446 \pm 159$ (SE) L per day for the whole blood clearance rate. The corresponding ratios for three pregnant subjects were 1.39, 1.41, and 1.42 , with a mean value of 1.41 , giving a calculated MCR of $2,176 \pm 159$ (SE) L of whole blood per day in pregnancy.

\section{DISCUSSION}

The estimation of MCR by the single-injection and constant-infusion methods gives the same result to within 10 per cent (a 20 per cent difference could have been detected). This confirms that the methods are technically adequate, that the tritiated aldosterone isolated from the plasma is radiochemically pure, that the second phase of the disappearance curve after single injection can reasonably be represented by a single exponential function, and that the plasma concentration after the constant infusion is constant. Few fundamental conclusions, however, can be drawn from the equivalence of the estimates, because (see Appendix) the MCR values calculated by both methods will be equal whether the hormone is secreted into the outer pool or not, although the estimate may not be valid if both secretion and metabolism occur in this compartment. However, because the maternal adrenal secretes nearly all the aldosterone in pregnancy, the estimates are likely to be valid for this hormone even in this condition. The agreement between the two methods does indicate that two compartments are adequate in order to arrive at estimates of MCR of the required accuracy to describe the metabolism and transport of aldosterone. If the second exponential function of the plasma disappearance curve after a single injection were due to significant extent to slow mixing into a third compartment, the two methods would not be expected to agree. This is particularly so as the plasma concentration is followed for a much longer time after constant infusion (135 minute) than is possible routinely after the single injection (70 minutes). In a previous paper (4) this possibility was examined by following the plasma radioactivity after a single injection for 120 minutes for two subjects. It was concluded that the semilogarithmic plot was a straight line for this length of time. The constant plasma concentrations of radioactivity after constant infusion also make this source of error unlikely. This does not exclude the possibility that aldosterone to some extent slowly enters other compartments, such as that containing cerebrospinal fluid, but the evidence indicates that if this does occur, it will not significantly affect the estimates of MCR, considering the over-all accuracy of the method.

The MCR found for thirteen nonpregnant subjects of $1,631 \pm 106(\mathrm{SE})$ or $\pm 366(\mathrm{SD}) \mathrm{L}$ of plasma per day agrees with our previous estimate (4). The comparison of values for the 
metabolic clearance for plasma and whole blood in nonpregnant subjects indicates that only 11 per cent of the radioactivity as aldosterone in whole blood after constant infusion of the tritiated hormone is associated with the red cells (hematocrit, 41 per cent).

The MCR for aldosterone calculated as 2,446 \pm 159 (SE) L of whole blood per day is approximately equal to estimates of total hepatic blood flow of $2,395 \pm 300$ (SE) L per day (10); 2,174 (11) by the denatured $\mathrm{I}^{131}$ albumin method ; 2,102 $(10,12)$ and 2,448 (13) by indocyanine green; and 2,156, 1,996, and 2,467 $\mathrm{L}$ of whole blood per day (14-17) by bromsulfalein, with all estimates carried out on recumbent subjects. The unweighted mean of these estimates is 2,250 , compared with the MCR aldosterone value of 2,446 $\pm 159 \mathrm{~L}$ of whole blood per day. If, as is the case in the dog (9), there is little extrahepatic metabolism of aldosterone in nonpregnant subjects, this agreement between the values for the MCR of aldosterone and the total hepatic blood flow indicates that all the aldosterone entering is metabolized in one passage through the liver. This justifies the hypothetical inclusion of the plasma and the liver into a common inner pool of a two-compartment model to describe the metabolism and transport of aldosterone (4). It also suggests that the hepatic blood flow may be a factor in determining plasma concentrations of aldosterone, as also suggested by Dobson (18).

When the hepatic extraction is initially about 50 per cent, as for bromsulfalein, the extraction is dependent on hepatic blood flow (15), but the clearance is nearly independent of the flow. When the extraction approaches 100 per cent it is much more likely that it will be independent of blood flow and therefore that the clearance rate will be proportional to the hepatic blood flow. The report of Coppage, Island, Cooner, and Liddle (19) that aldosterone given orally is less than 10 per cent as active as that administered parenterally and that this weak activity is not due to poor absorption supports the suggestion that the hepatic extraction of aldosterone is nearly 100 per cent. Thus in the normal subject aldosterone may be totally inactivated in one passage through the liver. The consequent correlation of hepatic blood flow and MCR may be significant in certain physiological situations, such as bringing a subject from the recumbent to the upright position, as a factor in quickly changing plasma concentrations of aldosterone $(4,17)$.

The MCR of aldosterone in pregnancy near term is $1,543 \pm 113$ (SE) L of plasma per day and $2,176 \pm 159$ (SE) L of whole blood per day, equivalent to the value in nonpregnant subjects. Interpretation of this result is made difficult because nothing is known directly of the extrahepatic metabolism in pregnancy. With the bromsulfalein method, the hepatic blood flow has been found to be the same for pregnant and nonpregnant subjects (16). In the case of cortisol, it has been suggested that there is a reduction in MCR in pregnancy (20) that is due at least in part to an increase in relative binding of cortisol to plasma proteins, apparently caused by estrogens (21). Presumably this would act to reduce hepatic extraction. The same mechanism is unlikely to reduce MCR of aldosterone, since it has been shown that there is little increase of plasma binding of this hormone in pregnancy $(2,3)$.

The excretion of tetrahydroaldosterone glucuronide, expressed as a fraction of secreted hormone, is reduced in pregnancy, but that of the acid-hydrolyzable conjugate, i.e., the conjugate that is hydrolyzed by acid conditions to yield aldosterone itself, is increased $(1,22)$. This is unlikely to be due to the effects of estrogen, since only minor alterations in the pattern of excretion of metabolites occur even when large amounts of ethynyl-estradiol 3-methyl ether are administered (23), although the small change observed is of the same nature as seen in pregnancy. It does suggest that for some unknown reason the metabolism of aldosterone to tetrahydroaldosterone glucuronide in the liver is inhibited in pregnant subjects and that the increase in the acid-hydrolyzable conjugate may be a compensatory mechanism that maintains hepatic extraction at 100 per cent. It is of interest that Hurter and Nabarro (24) and Coppage and co-workers (19) have reported that in certain cases of cirrhosis, the pattern of excretion of metabolites of aldosterone is similar to that reported in pregnancy (1). This suggests that the enzyme systems responsible for formation of tetrahydroaldosterone are more easily inhibited than those concerned with the acid-hydrolyzable conjugate in both cirrhosis and pregnancy. 
Since the MCR of aldosterone in pregnancy is unchanged, the increases in secretion rate of the hormone in that condition $(1,25)$ must be accompanied by increases in concentration of the hormone in plasma, and studies on the binding of the steroid to plasma proteins in this condition indicate that the unbound aldosterone will also increase. Whether such increases might be expected to lead to greater disturbances of electrolyte metabolism in pregnancy than are observed, or whether they are a consequence of the salt-excreting effects of progesterone or of some other stimulation $(1,26)$ is still unknown.

\section{SUMMARY}

A theoretical treatment of the single-injection and constant-infusion methods for estimating metabolic clearance rates (MCR; secretion rate/ plasma or whole blood concentration) is given with a two-compartment model with metabolism and secretion occurring in both pools. It is concluded that the estimates ought to be equal under all conditions considered. The estimates will be valid if secretion into or metabolism in the outer pool is zero.

Experimentally, a comparison of estimates carried out by both methods has found them to be equivalent in both pregnant and nonpregnant subjects. The combined estimates with both methods were not significantly different between nonpregnant and pregnant subjects-1,631 \pm $106(\mathrm{SE})$ and $1,543 \pm 113(\mathrm{SE}) \mathrm{L}$ of plasma per day, respectively.

The MCR for plasma and whole blood has been compared in six subjects. With the ratio obtained, the MCR for whole blood has been calculated as $2,446 \pm 159$ (SE) for nonpregnant and $2,176 \pm 159$ (SE) L of whole blood per day for pregnant subjects.

The similarity in the values for the MCR of aldosterone to estimates of total hepatic blood flow for both pregnant and nonpregnant subjects is noted. It is suggested that, since the hepatic extraction of aldosterone may be about 100 per cent, the hepatic blood flow may be a factor in the control of aldosterone metabolism and hence of peripheral plasma concentration.

\section{APPENDIX}

For the purposes of describing the metabolism and transport of aldosterone, or of any steroid whose plasma disap- pearance curve after a single injection can be described adequately by two exponential functions, let the body be represented by two compartments. The radioactive steriod is introduced into the inner pool, which includes the plasma.

The whole of the inner pool is assumed to be in rapid equilibrium with the plasma. Transport of steriod into the other, outer pool is relatively slow. These pools are not necessarily well-defined anatomically. In pregnancy, however, the possibility must be considered that the fetus is part of the outer pool, and that secretion, or metabolism of the hormone, or both may occur there. Metabolism and secretion of the hormone are therefore assumed, in the general case, to occur in both pools.

Let $S_{1}=$ secretion rate into inner pool, $S_{2}=$ secretion rate into outer pool, $S=S_{1}+S_{2}=$ total secretion rate, $I=$ steroid content of inner pool, $Q=$ steroid content of outer pool, $i=$ steroid concentration in inner pool (including plasma), $a=$ steroid metabolized in inner pool in unit time, $e=$ steroid metabolized in outer pool in unit time, $b=$ steroid transferred from inner to outer pool in unit time, $b^{1}=$ steroid transferred from outer to inner pool in unit time, $\theta_{1}=$ fraction of steroid in inner pool transferred to outer pool in unit time $(b / I), \theta_{2}=$ fraction of steroid in outer pool transferred to inner pool in unit time $\left(b^{1} / Q\right), \theta_{3}=$ fraction of steroid in inner pool metabolized in unit time $(a / I), \theta_{4}=$ fraction of steroid in outer pool metabolized in unit time $(e / Q), x=$ fraction of injected radioactivity (measured specifically as the hormone) in inner pool at time $t, z=$ fraction of injected radioactivity (measured specifically as the hormone) in outer pool at time $t, x^{1}=$ fraction of injected radioactivity as concentration in inner pool (equal to that in plasma) at time $t$, and $V_{1}=$ the volume of the inner pool $(I / i)$.

Dynamic equations are

and

$$
-d x / d t=\theta_{1} x-\theta_{2} z+\theta_{3} x
$$

$$
d z / d t=\theta_{1} x-\theta_{2} z-\theta_{4} z
$$

assuming first-order individual reaction, homogeneity of the two pools, and no recirculation of isotope after metabolism. Steady state requirements are

$$
\theta_{4} Q+\theta_{3} I=S_{1}+S_{2}=S,
$$

since total rates of metabolism and secretion must be equal. Also, for no net accumulation or disappearance in pool,

$$
\begin{gathered}
\left(\theta_{2}+\theta_{4}\right) Q-\theta_{1} I=S_{2}, \\
\left(\theta_{3}+\theta_{1}\right) I-\theta_{2} Q=S_{1}, \\
S_{1}+b^{1}=a+b, \\
S_{2}+b=b^{1}+e .
\end{gathered}
$$

and

Then

$I / S=\left(\left[\theta_{2}+\theta_{4}\right] /\left[\theta_{2} \theta_{3}+\theta_{4} \theta_{3}+\theta_{4} \theta_{1}\right]\right)$

$$
\times\left(1-\left[S_{2} e / S\left(S_{2}+b\right)\right]\right) \text {. }
$$

Single injection. $x=A e^{-\alpha t}+B e^{-\beta t}$ is the solution of Equations 1 and 2, and

$$
\begin{gathered}
\alpha+\beta=\theta_{1}+\theta_{2}+\theta_{3}+\theta_{4}, \\
\alpha \beta=\theta_{2} \theta_{3}+\theta_{4} \theta_{3}+\theta_{4} \theta_{1}, \\
A \alpha+B \beta=\theta_{1}+\theta_{3},
\end{gathered}
$$


and

$$
A \beta+B \alpha=\theta_{2}+\theta_{4} .
$$

As pointed out in references (4) and (6), these equations cannot be solved for $\theta_{1}, \theta_{2}, \theta_{3}$, or $\theta_{4}$, nor for $(I+Q) / i=$ the final volume of distribution, unless $\theta_{3}$ or $\theta_{4}$, metabolism in either pool, is made equal to zero.

In all cases, however,

$$
V_{1}=1 /\left(A^{1}+B^{1}\right),
$$

being the reciprocal of the plasma concentration at zero time. $x^{1}$ (the plasma concentration at time $\left.t\right)=A^{1} e^{-\alpha t}$ $+B^{1} e^{-\beta \mathrm{t}}$,

and

$$
\left(A^{1} \alpha+B^{1} \beta\right) /\left(A^{1}+B^{1}\right)=\theta_{1}+\theta_{3}
$$
from $[11]$ and $[13]$

$$
\left(A^{1} \beta+B^{1} \alpha\right) /\left(A^{1}+B^{1}\right)=\theta_{2}+\theta_{4}
$$
from $[12]$ and $[13]$

$A^{1}, B^{1}, \alpha$, and $\beta$ are the experimentally determined quantities.

Then $\mathrm{MCR}=$ total secretion rate/concentration of nonisotopic steroid in plasma $=S / i$, by definition. As before,

$$
\begin{aligned}
I / S=\left(\left[\theta_{2}+\theta_{4}\right] /\left[\theta_{2} \theta_{3}+\theta_{4} \theta_{3}+\theta_{4} \theta_{1}\right]\right) & \times\left(1-\left[S_{2} e / S\left(S_{2}+b\right)\right]\right),
\end{aligned}
$$

and from Equations 10, 12, 13, 15, and

$$
\begin{gathered}
i / S=\left(\left[A^{1} \beta+B^{1} \alpha\right] / \alpha \beta\right)\left(1-\left[S_{2} e / S\left(S_{2}+b\right)\right]\right), \\
M C R=\left(\alpha \beta /\left[A^{1} \beta+B^{1} \alpha\right]\right)\left(\frac{1}{1-S_{2} e /\left[S\left(S_{2}+b\right)\right]}\right) .
\end{gathered}
$$

Let the estimated MCR value

$$
M C R_{E}=\alpha \beta /\left(A^{1} \beta+B^{1} \alpha\right) .
$$

Then the true MCR $=M C R_{E} \times f$, and

$$
f=\frac{1}{1-S_{2} e /\left[S\left(S_{2}+b\right)\right]}
$$

Constant infusion. Let $r=$ rate of infusion of radioactive steroid (fraction of total infused radioactivity in unit time). Then

and

$$
d x / d t=-\left(\theta_{1}+\theta_{3}\right) x+\theta_{2} z+r
$$

$$
d z / d t=\theta_{1} x-\theta_{2} z-\theta_{4} z .
$$

The infusion is continued until $x$ is constant, as determined experimentally, when $z$ must also be constant. Then

and

$$
d x / d t=0=d z / d t \text { at } x_{c}
$$

$$
r=\left(\left[\theta_{1} \theta_{4}+\theta_{2} \theta_{3}+\theta_{4} \theta_{3}\right] /\left[\theta_{2}+\theta_{4}\right]\right) x_{c}
$$

from Equations 18, 19, and 20. Then

and

$$
\frac{S}{I}=\frac{r}{x_{c}}\left(\frac{1}{1-S_{2} e /\left[S\left(S_{2}+b\right)\right]}\right)
$$

$$
\frac{S}{i}=M C R=\left(\frac{r}{x_{c}^{1}}\right)\left(\frac{1}{1-S_{2} e /\left[S\left(S_{2}+b\right)\right]}\right) .
$$

Then let the estimated MCR

$$
M C R_{E}=r / x_{c}^{1}
$$

and the true $\mathrm{MCR}=M C R_{E} \times f$, where

$$
f=\frac{1}{1-S_{2} e /\left[S\left(S_{2}+b\right)\right]} .
$$

Therefore, in the general case for both the constantinfusion and the single-injection methods, the estimates of Equations 16 and 22 will give the same result. $M C R$ $=M C R_{E} \times f$, and $f$ is the same for both Equations 17 and 23. If $f=1$, this estimate will be valid, and this will be the case when either $S_{2}$ or $e$ is zero, i.e., when secretion or metabolism is negligible in the outer pool. It should be noted that these criteria for validity of the MCR methods are similar to those for the valid calculation of secretion rates from the specific activity of a urinary metabolite (27).

\section{REFERENCES}

1. Jones, K. M., Lloyd-Jones, R., Riondel, A., Tait, J. F., Tait, S. A. S., Bulbrook, R. D., and Greenwood F. C. Aldosterone secretion and metabolism in normal men and women and in pregnancy. Acta endocr. (Kbh.) 1959, 30, 321.

2. Daughaday, W. H., Holloszy, J., and Mariz, I. K. Binding of corticosteroids by plasma proteins. VI. The binding of cortisol and aldosterone by corticosteroid-binding globulin and by the estrogeninduced binding system of plasma. J. clin. Endocr. 1961, 21, 53.

3. Meyer, C. J., Layne, D. S., Tait, J. F., and Pincus, G. The binding of aldosterone to plasma proteins in normal, pregnant, and steroid-treated women. J. clin. Invest. 1961, 40, 1663.

4. Tait, J. F., Tait, S. A. S., Little, B., and Laumas, $\mathrm{K}$. R. The disappearance of $7-\mathrm{H}^{3}-d$-aldosterone in the plasma of normal subjects. J. clin. Invest. 1961, 40, 72.

5. Bush, I. E., and Sandberg, A. A. Adrenocortical hormones in human plasma. J. biol. Chem. 1953, 205, 783.

6. Christy, N. P., and Jailer, J. W. Failure to demonstrate hydrocortisone and aldosterone during pregnancy in Addison's disease. J. clin. Endocr. 1959, 19, 263.

7. Baulieu, E-E., de Vigan, M., Bricaire, H., and Jayle, M-F. Lack of plasma cortisol and urinary aldosterone in a pregnant woman with Addison's disease. J. clin. Endocr. 1957, 17, 1478.

8. Laidlaw, J. C., Cohen, H., Gornall, A. G. Studies on the origin of aldosterone during human pregnancy. J. clin. Endocr. 1958, 18, 222.

9. Ayers, C. R., Davis, J. O., Lieberman, F., Carpenter, C. C. J., and Berman, M. The effects of chronic hepatic venous congestion on the metabolism of $d, l$-aldosterone and $d$-aldosterone. J. clin. Invest. 1962, 41, 884.

10. Shaldon, S., Chiandussi, L., Guevara, L., Caesar, J., and Sherlock, S. The estimation of hepatic blood 
flow and intrahepatic shunted blood flow by colloidal heat-denatured human serum albumin labeled with $\mathrm{I}^{131}$. J. clin. Invest. 1961, 40, 1346.

11. Halpern, B. N., Biozzi, G., Pequignot, G., Delaloye, C., Stiffel, C., and Mouton, D. Mesure de la circulation sanguine du foie et de l'activité phagocytaire du système reticulo-endothelial chez le sujet normal et le sujet cirrhotique. Path. et Biol. 1959, 7, 1637.

12. Caesar, J., Shaldon, S., Chiandussi, L., Guevara, L., and Sherlock, S. The use of indocyanine green in the measurement of hepatic blood flow and as a test of hepatic function. Clin. Sci. 1961, 21, 43.

13. Reemtsma, K., Hottinger, G. C., De Graff, Jr., A. C. and Creech, O., Jr. The estimation of hepatic blood flow using indocyanine green. Surg. Gynec. Obstet. 1960, 110, 353.

14. Bradley, S. E., Ingelfinger, F. J., Bradley, G. P., and Curry, J. J. The estimation of hepatic blood flow in man. J. clin. Invest. 1945, 24, 890.

15. Bradley, S. E., Ingelfinger, F. J., and Bradley, G. P. Determinants of hepatic haemodynamics in Ciba Foundation on Visceral Circulation, G. E. W. Wolstenholme, Ed. Boston, Little, Brown, 1953, p. 219.

16. Munnell, E. W., and Taylor, H. C., Jr. Liver blood flow in pregnancy-hepatic vein catheterization. J. clin. Invest. 1947, 26, 952.

17. Culbertson, J. W., Wilkins, R. W., Ingelfinger, F. J., and Bradley, S. E. The effect of the upright posture upon hepatic blood flow in normotensive and hypertensive subjects. J. clin. Invest. 1951, 30, 305.

18. Dobson, E. L. The homeostatic regulation of body fluid volumes in Homeostatic Mechanisms, Brookhaven Symposia in Biology, No. 10. Brookhaven
National Laboratory, Upton, New York, 1958, p. 197.

19. Coppage, W. S., Island, D. P., Conner, A. E., and Liddle, G. W. The metabolism of aldosterone in normal subjects and in patients with hepatic cirrhosis. J. clin. Invest. 1962, 41, 1672.

20. Migeon, C. J., Bertrand, J., and Wall, P. E. Physiological disposition of 4- ${ }^{14}$-cortisol during late pregnancy. J. clin. Invest. 1957, 36, 1350.

21. Mills, I. H., Schedl, H. P., Chen, P. S., Jr., and Bartter, F. C. The effect of estrogen administration on the metabolism and protein binding of hydrocortisone. J. clin. Endocr. 1960, 20, 515.

22. Venning, E. H., and Dyrenfurth, I. Excretion of various corticosteroids and their reduced metabolites throughout pregnancy. Acta endocr. (Kbh.) 1960, suppl. 51, 665 .

23. Layne, D. S., Meyer, C. J., Vaishwanar, P. S., and Pincus, G. The secretion and metabolism of cortisol and aldosterone in normal and in steroidtreated women. J. clin. Endocr. 1962, 22, 107.

24. Hurter, R., and Nabarro, J. D. N. Aldosterone metabolism in liver disease. Acta endocr. (Kbh.) 1960, 33, 168.

25. Van de Wiele, R. L., Gurpide, E., Kelly, W. G., Laragh, J. H., and Lieberman, S. The secretory rate of progesterone and aldosterone in normal and abnormal late pregnancy. Acta endocr. (Kbh.) 1960, suppl. 51, 159.

26. Ehrlich, E. N., Laves, M., Lugibihl, K., and Landau, R. L. Progesterone-aldosterone interrelationships in pregnancy. J. Lab. clin. Med. 1962, 59, 588.

27. Laumas, K. R., Tait, J. F., and Tait, S. A. S. Further considerations on the calculations of secretion rates. A correction. Acta endocr. (Kbh.) 1961, $38,469$.

\section{SPECIAL NOTICE TO SUBSCRIBERS}

Post Offices will no longer forward the Journal when you move.

Please notify The Journal of Clinical Investigation, Business Office, 10 Stoughton Street, Boston 18, Mass., at once when you have a change of address, and do not omit the zone number if there is one. 